\title{
Lifestyle patterns and the prevalence of hypertension among the teachers of Kashmir University (Age 35 to 60 years)
}

See end of the paper for authors' affiliations

\section{SANIA SHAKEEL}

Institute of Home Science, University of

Kashmir, Hazratbal, SRINAGAR (J\&K)

INDIA

Email : shakeel_sania@yahoo.com
ABSTRACT : Background: Lifestyle factors are critical determinants of blood pressure levels. With urbanisation and increasing prosperity, prevalence of hypertension is on rise, about 60 per cent population of Kashmir is hypertensive and lifestyle is an important risk factor for it. Hypertension thus, becomes an increasingly important clinical problem. Objectives : To study the prevalence of high blood pressure among the teachers of Kashmir University (age group $35+$ ), to observe the relationship between the different parameters of lifestyle and hypertension. Methods: 106 participants (age 35+ to 60 years) from Kashmir University undertaken for the study were examined using both questionnaires as well as monitored twice a day (before and after work) for their blood pressures to check the diurnal variations. This study was a casecontrol study. The analysis of the data was done using t-test, $\chi 2$-test, $p$-value, and odd ratios, respectively. Results: The prevalence was 31 per cent and more in males. A strong relationship was found between workload and diurnal variations in blood pressure ( $\mathrm{p}$-value $<0.01$ ). Physical inactivity, skipping of meals, type of the salt was found to have a direct relationship in the development of hypertension ( $\mathrm{p}$-value $<0.05$ ). However other parameters like high socio-economic status, stress, waistline obesity, high body mass index (BMI), sleeping patterns, work hours, smoking, and intake of fat, salt and dietary patterns were important risk factors which could be the contributors in the development of hypertension. Conclusion : It was thus concluded that a healthy lifestyle helps in preventing hypertension. And lifestyle modifications like physical activity, reduction of weight, reducing dietary sodium, stress free life and a good diet can surely help in maintain controlled blood pressure.

KEY WORDS: Hypertension, Diet, Lifestyle, Stress, Lifestyle diseases, Obesity

- HOW TO CITE THIS PAPER : Shakeel, Sania and Irshad, Naila (2016). Lifestyle patterns and the prevalence of hypertension among the teachers of Kashmir University (Age 35 to 60 years). Asian J. Home Sci., 11 (2) : 404-409, DOI: 10.15740/HAS/AJHS/11.2/404-409. 